Review

\title{
Pharmacist's Use of Screening Tools to Estimate Risk of CVD: A Review of the Literature
}

\author{
Dónal Og O'Donovan ${ }^{1}$, Stephen Byrne ${ }^{1}$ and Laura J. Sahm ${ }^{1,2, *}$ \\ 1 Pharmaceutical Care Research Group, School of Pharmacy, University College Cork, Cork 30, \\ Ireland; E-Mails: donal.odonovan@ucc.ie (D.O.O.); Stephen.byrne@ucc.ie (S.B.) \\ Department of Pharmacy, Mercy University Hospital, Grenville Place, Cork 30, Ireland \\ * Author to whom correspondence should be addressed; E-Mail: L.Sahm@ucc.ie; \\ Tel.: +353-214-901-688; Fax: +353-214-901-656.
}

Received: 19 August 2013; in revised form: 29 November 2013 / Accepted: 6 December 2013 / Published: 9 January 2014

\begin{abstract}
To review pharmacist-led screening programmes for estimation of cardiovascular disease (CVD) risk using validated screening tools, studies were identified using a search of the following electronic databases: PubMed, EMBASE, Web of Knowledge and the Cochrane library databases. Each database was searched from inception to December 2011. The search terms used were: "cardiovascular disease", "screening", "risk estimation", "pharmacist" and "pharmacy". Titles, abstracts and full manuscripts were screened to determine eligibility. Inclusion criteria were: (i) Pharmacist-led CVD screening; and (ii) Use of validated screening tool or tools for CVD. From each included study information was collected on the following: Study author; year of publication; setting; inclusion and exclusion criteria; tools used and outcomes measured. Articles were grouped and independently verified to ensure they met with the inclusion criteria. Over 7,000 citations were found. Twenty full-length articles were retrieved for analysis, of which twelve were excluded, as they did not meet the inclusion criteria. The eight remaining articles were included in this literature review. Whilst pharmacists undertake screening in their own practice, this approach will only go so far. To have a population-health impact, pharmacists should be involved in proactive screening in a variety of settings.
\end{abstract}

Keywords: CVD; pharmacist; screening tools; review 


\section{Introduction}

Cardiovascular disease (CVD) is currently the leading cause of death in the world [1]. At the beginning of the 20th century, CVD accounted for less than $10 \%$ of all global deaths, but by the year 2000, CVD was responsible for nearly half of all deaths in the developed world, and a quarter of deaths in the developing world [2]. Most recent World Health Organisation (WHO) figures estimate that CVD caused the death of 17.3 million people in 2008 [3]. This was the largest cause of death, representing $30 \%$ of all deaths that year. CVD is predicted to remain the number one cause of death globally for the foreseeable future [3].

The rationale for preventing CVD is straightforward: to reduce CVD events and prevent mortality due to CVD. Unfortunately the healthcare budget is a finite resource and although spending time and money on preventing CVD events is a very worthwhile use, highest priority goes to those who have already been diagnosed with CVD. Nonetheless there is enormous benefit in treating those people who are at risk of developing CVD [4].

Non-identification of this at-risk group can have serious consequences. It has been estimated that at least $25 \%$ of CVD patients have sudden cardiac death or non-fatal myocardial infarction (MI) without prior symptoms or knowledge of their existing CVD [5]. Studies have shown that many physicians rely on subjective methods to estimate risk of developing CVD [6,7], however these methods tend to underestimate the actual risk [8]. For this reason national guidelines recommend the use of validated and objective screening tools for estimation of CVD risk $[9,10]$. One of the advantages of having an objective screening tool is that it does not require medical training and can be applied by pharmacists (and other healthcare professionals). Several screening tools have been developed to measure risk of CVD, including Framingham, QRISK2, ASSIGN and SCORE [11-14]. The Framingham risk score (FRS) is the most widely used screening tool globally[12,15]. Although each screening tool ultimately measures risk of developing CVD, there are some differences in outcome, for instance SCORE measures risk of mortality due to CVD [16].

In recent years there have been many calls to broaden the role of the community pharmacist beyond the traditional product-orientated functions of dispensing and distributing medication, to include a greater role in public health [17]. A 2004 paper by van Mil et al. contains the following passage:

"Pharmacists should move from behind the counter and start serving the public by providing care instead of pills only... The fact that pharmacists have an academic training and act as health care professionals puts a burden upon them to better serve the community than they currently do" [18].

The WHO have created a "seven-star concept", in which a pharmacist is described as a caregiver, communicator, decision-maker, teacher, lifelong learner, leader and manager and is thus perfectly positioned to carry out effective interventions [19]. One of the benefits of a pharmacist acting under the direction of this "seven-star" concept is that it will facilitate them to successfully carry out interventions which have been shown to improve the clinical outcomes of patients [20]. Intervention programmes involving the community pharmacist have been shown to be successful, and can generate benefits that are ten times greater than the costs [21].

Pharmacist-led interventions have been shown to be feasible in a number of areas relevant to CVD, such as: 
- medication use [22];

- management of CVD [23,24];

- diabetes mellitus (DM) [25,26];

- hypertension [27,28]; and

- heart failure [29].

To date, however there are no systematic reviews that we are aware of, which document the pharmacist-led screening programmes for estimation of CVD risk. This review addresses this gap in the literature.

The aim of this systematic literature search was to review pharmacist-led screening programmes for estimation of CVD risk using validated screening tools, i.e., where the pharmacist is the healthcare professional who conducts the screening. This was achieved by the following objectives:

- To examine the location of pharmacist-led CVD screening programmes.

- To record the screening tools used in pharmacist-led CVD screening programmes.

- To determine the prevalence, in the literature, of pharmacist-led CVD screening programmes.

- To determine the outcomes measured by pharmacists, both primary and secondary, during their screening services.

\section{Experimental Section}

A systematic review of the literature was conducted. Studies were identified using a search of the following electronic databases: PubMed, EMBASE, Web of Knowledge and the Cochrane library databases. Each database was searched from inception to December 2011. The search terms used were: "cardiovascular disease", "screening”, "risk estimation", "pharmacist" and "pharmacy". Combinations of these search terms were used. Only original research articles in English and pertaining to humans were accepted. In addition, to capture any publications not found by the search strategy, references from retrieved studies were searched by hand for any relevant citations.

The primary researcher (Dónal Óg O’Donovan) screened titles, abstracts and full manuscripts to determine eligibility in this literature review. Inclusion criteria were:

- Pharmacist-led CVD screening (CVD risk estimates, as performed by pharmacists using a validated screening tool(s));

- Use of validated screening tool or tools for CVD.

Primary outcomes of interest for this review were CVD risk estimates, as performed by pharmacists using (a) validated screening tool(s). Secondary outcomes of interest were location of screening, screening tools used and other CVD risk factors measured (such as age, lipid profile, systolic blood pressure (SBP), diastolic blood pressure (DBP), High-Density Lipoprotein Cholesterol (HDL-C) levels, recruitment process and smoking status).

Data extraction was performed by the primary researcher. From each included study information was collected on the following:

- Study author;

- Year of publication; 
- Setting and country where the study was conducted;

- Inclusion and exclusion criteria;

- Screening tool(s) used;

- Outcomes measured.

Articles were grouped in a Microsoft Excel ${ }^{\circledR} 2003$ spreadsheet and were independently verified by all the researchers to ensure they met with the inclusion criteria.

\section{Results and Discussion}

Figure 1 describes how the studies were assessed for inclusion whilst Table 1 gives an overview of the characteristics of each of the included studies.

Figure 1. Flow diagram of studies assessed and included.

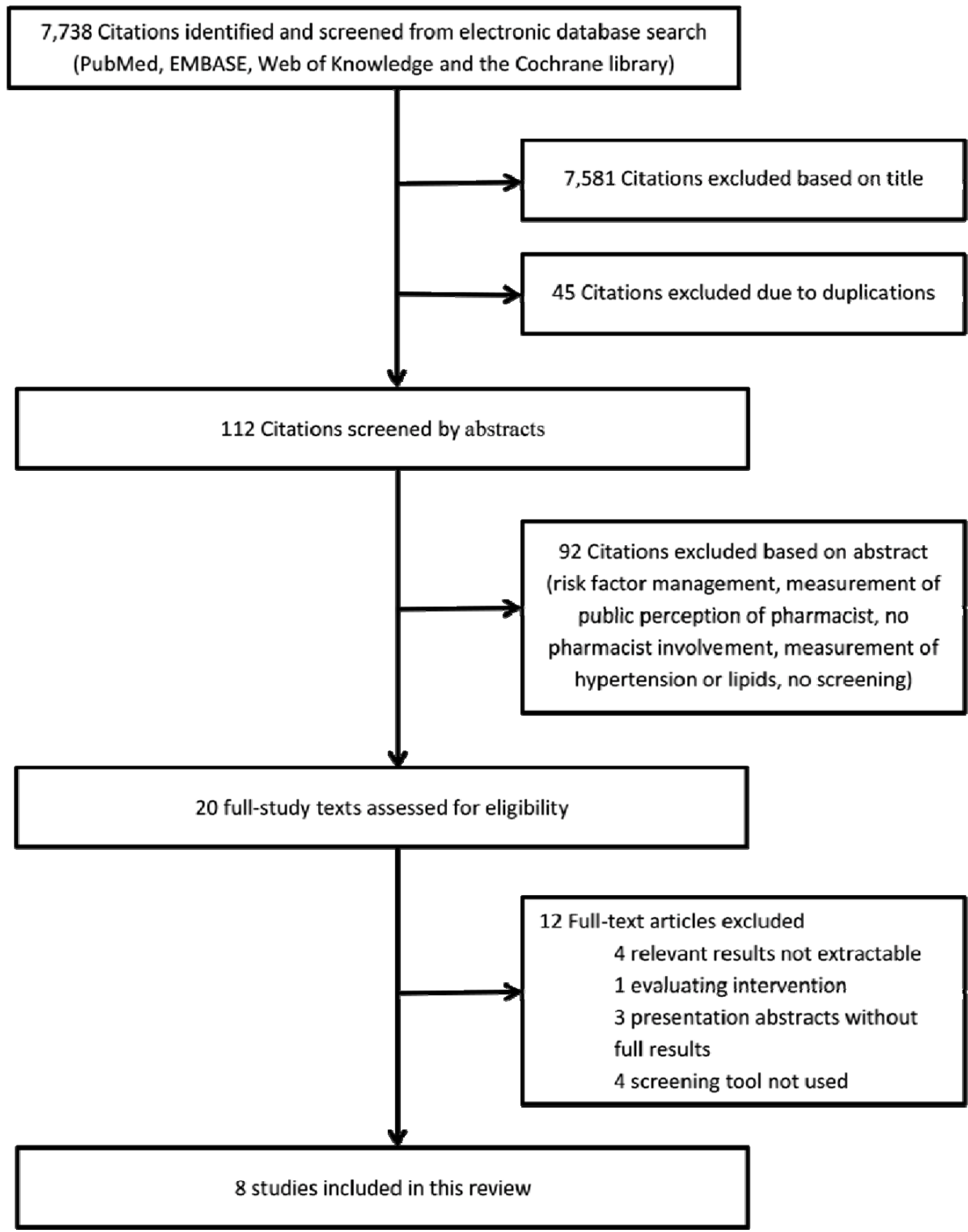


Table 1. Characteristics of included studies.

\begin{tabular}{|c|c|c|c|c|c|c|}
\hline Source; Country & Setting & Recruitment & $\mathbf{n}$ & Inclusion Criteria & Exclusion Criteria & Screening Tool Used \\
\hline $\begin{array}{l}\text { Evans et al., } \\
2010 \text { [30]; Canada }\end{array}$ & $\begin{array}{l}\text { General Practitioner } \\
\text { (GP) practice }\end{array}$ & referral & 252 & referral & $\begin{array}{l}\text { severe psychiatric conditions, } \\
\text { heart failure, terminal illness, } \\
\text { pregnancy, lactation }\end{array}$ & $\begin{array}{l}\text { 10-year risk of cardiac death or non- } \\
\text { fatal myocardial infarction (MI) based } \\
\text { on Framingham risk score (FRS) tool } \\
\text { recommended by Canadian } \\
\text { Cardiovascular Society }\end{array}$ \\
\hline $\begin{array}{l}\text { Peterson et al., } \\
2010 \text { [31]; Australia }\end{array}$ & Community pharmacy & opportunistic screening & 640 & $\begin{array}{l}\text { minimum age } \\
30 \text { years }\end{array}$ & $\begin{array}{l}\text { diagnosed hypertension, } \\
\text { hyperlipidaemia or } \\
\text { cardiovascular disease (CVD) }\end{array}$ & $\begin{array}{l}\text { 10-year cardiovascular risk calculated } \\
\text { using a modified version of the } \\
\text { New Zealand Cardiovascular } \\
\text { Risk Calculator }\end{array}$ \\
\hline $\begin{array}{l}\text { Donyai et al., } \\
2009 \text { [32]; UK }\end{array}$ & Community pharmacy & not clear & 8,287 & not clear & not clear & $\begin{array}{l}\text { Framingham risk calculator for } \\
10 \text {-year risk of Coronary Heart } \\
\text { Disease ( CHD) }\end{array}$ \\
\hline $\begin{array}{l}\text { De Oliveira } \\
\text { Martins et al., } \\
2008 \text { [33]; Portugal }\end{array}$ & Community pharmacy & opportunistic screening & 1,043 & age $40-65$ & $\begin{array}{l}\text { cognitive impairment, } \\
\text { inability to understand } \\
\text { local language }\end{array}$ & $\begin{array}{l}\text { 10-year risk of fatal CVD calculated } \\
\text { by SCORE model for low-risk regions }\end{array}$ \\
\hline $\begin{array}{l}\text { Taveira et al., } \\
2006 \text { [24]; USA }\end{array}$ & $\begin{array}{l}\text { Cardiovascular Risk } \\
\text { Reduction Clinic }\end{array}$ & referral & 355 & referral & not clear & $\begin{array}{l}10 \text {-year risk of cardiac events } \\
\text { as measured by Framingham } \\
\text { Points Score }\end{array}$ \\
\hline $\begin{array}{l}\text { Liu et al., } \\
2008 \text { [34]; USA }\end{array}$ & $\begin{array}{l}\text { Union Hall } \\
\text { for tradesmen }\end{array}$ & opportunistic screening & 265 & $\begin{array}{l}\text { member of a trade } \\
\text { union or dependent } \\
\text { of member }\end{array}$ & not clear & $\begin{array}{l}\text { Framingham risk calculator for } \\
10 \text {-year risk of CHD }\end{array}$ \\
\hline $\begin{array}{l}\text { Olenak et al., } \\
2008 \text { [35]; USA }\end{array}$ & Community pharmacy & opportunistic screening & 86 & minimum age 18 & $\mathrm{DM}$ or diagnosed (CHD) & $\begin{array}{l}\text { Framingham risk calculator for } \\
10 \text {-year risk of CHD }\end{array}$ \\
\hline $\begin{array}{l}\text { Horgan et al., } \\
2010 \text { [36]; USA }\end{array}$ & Community pharmacy & opportunistic screening & 1,130 & age $40-70$ & $\begin{array}{l}\text { recently screened for CVD } \\
\text { by General Practitioner (GP) } \\
\text { or prescribed medication for } \\
\text { existing CVD }\end{array}$ & $\begin{array}{l}\text { Framingham risk calculator for } \\
10 \text {-year risk of CHD }\end{array}$ \\
\hline
\end{tabular}




\subsection{Recruitment}

The inclusion criteria for each study in this review varied considerably. In five studies participants were recruited through opportunistic screening [31-33,35,36]. In some cases the screening service was advertised in both the pharmacy and in the local media. In one study the advertising was targeted to males at high risk of CVD [36]. For a further two studies, participants were referred for CVD screening [24,30]. For the remaining study [32] participant recruitment was not clear.

\subsection{Inclusion Criteria}

Similar to participant recruitment, inclusion criteria for the studies varied considerably. For both studies in which participants were referred by a doctor, the inclusion criteria were this referral $[24,30]$. For the paper by Liu et al. CVD risk screening was offered to members of unions and their dependents, and this was the only stated inclusion criterion [34]. In some cases screening was restricted to certain age groups, adults aged 40-70 years [36], adults aged 40-65 years [33], adults aged 30 years and over [31], and adults aged 18 years and over [35]. For the remaining study inclusion criteria were not stated [32].

\subsection{Exclusion Criteria}

Exclusion criteria were clearly defined for five studies. In many cases participants with a previous history of heart disease were excluded [30,31,35,36]. The study by Evans et al. [30] also excluded participants with severe psychiatric conditions, terminal illness, pregnancy and lactation. Participants diagnosed with DM were excluded in one study [36]. The study by de Oliveira Martins et al. [33] also excluded those with cognitive impairment and inability to speak the local language. Exclusion criteria were not defined for three studies included in the review [31,32,34].

\subsection{Screening Tools Used}

The most commonly used screening tool was the Framingham Screening tool. In total, six studies included in the review used a version of the Framingham Screening tool. Four studies used the Framingham Screening tool to estimate 10-year risk of coronary heart disease (CHD) [32,34,35,36]. Two studies included in this review used other versions of the Framingham screening tool. The study by Evans et al. [30] used a version of the Framingham screening tool for 10-year risk of cardiac death or non-fatal MI as recommended by the Canadian Cardiovascular Society. The study by Taveira et al. [24] used a measure of 10-year risk of cardiac events as measured by the Framingham Points Score. The remaining two studies used different screening tools to estimate risk of CVD. The study by Peterson et al. [31] was conducted in Australia and used a modified version of the New Zealand Risk Calculator for 10-year cardiovascular risk. Finally, the study by de Oliveira Martins et al. used the 10-year risk for fatal CVD calculated by the SCORE risk screening tool [33].

\subsection{CVD Risk}

The only outcome that was measured in all studies was CVD risk. Other outcomes measured varied between studies. This information is summarised in Table 2. 


\subsection{CVD Risk Estimate}

Only five studies reported a mean (or median) value of CVD risk estimate for their entire study population $[30,31,33,34,36]$. These results are summarised in Table 3. The mean CVD risk ranged from 1.97 to 14.7 and reflects the outcome measure of the screening tool, which varied from CVD risk to fatal CVD.

The remaining studies did not report the mean CVD risk of the population. Instead the proportion of the study population that was at high risk of developing CVD was reported [32,34-36]. These results are given in Table 4. The study by Donyai et al. is not included in this table because it used different criteria to report the risk profile. That study reported that $65 \%$ of the population $(n=5,377)$ were at low risk of CVD (defined as $<15 \%$ absolute risk of developing CHD over ten years). The remaining 35\% of the population $(n=2,910)$ were at moderate to high risk of CVD (defined as $>15 \%$ ten-year risk) [32].

\subsection{Other Risk Factors Reported}

The age profile of the population was described for only four of the studies, in which average age range varied from 53.7 to 62.0 years [30,33-35]. In total, six studies reported results concerning total cholesterol (TC). The results of five of these studies are shown in Table 5 [30,33-36]. Peterson et al. used different criteria to report results for the lipid profile. In this study it was reported that $21.3 \%$ of the population $(n=136)$ had a TC $>5.5 \mathrm{mmol} / \mathrm{L}$ [31]. Six studies also reported details of SBP in the study population [30,31,33-36]. The study by Peterson et al. did not report the mean SBP for the population, instead reporting that $30 \%$ of the study population $(n=192)$ had an SBP $>140 \mathrm{mmHg}$ [31]. No significant country-specific differences were found between the studies, and, therefore, this was not included as a variable.

In this review, eight studies were identified that showed the feasibility of pharmacists to screen for CVD. This compares very well with other work that has demonstrated the feasibility of other healthcare professionals to screen for CVD. There is a long track record of doctors screening for CVD, and all the major screening tools have been developed and validated using physicians [11,12,14,37,38]. It has also been shown that nurses can feasibly screen for CVD [39,40]. The variability in results reported makes it impossible to accurately compare screening results from pharmacists with results of other healthcare professionals.

The results of this study clearly demonstrate the potential value of pharmacists in identifying members of the population at risk of developing CVD. What is now needed is the proactive rather than reactive screening of members of the public by their pharmacist both in the pharmacy and other settings within the community. This is an opportunity for pharmacists to expand their role beyond the traditional functions mentioned earlier (dispensing and distributing medication) and playing a greater part in improving public health [17].

Pharmacists who move beyond the pharmacy setting could also increase uptake in those populations, which are marginalized or "hard to reach". Access-enhancing interventions can be defined as those which address the structural, financial and environmental barriers to screening i.e., bringing the service to the public in mobile screening units, the location of mobile screening units, access to transport to screening units and access to translated materials [41]. This approach has been implemented in cancer screening programmes and could be a worthwhile development for cardiovascular disease. 
Table 2. Outcomes measured in each study.

\begin{tabular}{|c|c|c|c|c|c|c|c|c|c|c|c|c|c|}
\hline Source, year & CVD Risk & Age & Sex & SBP * & DBP* & $\mathbf{T C} *$ & TG * & LDL * & HDL * & TC:HDL * & BG * & Smoking status & BMI * \\
\hline Evans et al., 2010 [30] & $\checkmark$ & $\checkmark$ & $\checkmark$ & $\checkmark$ & & $\checkmark$ & $\checkmark$ & $\checkmark$ & $\checkmark$ & $\checkmark$ & & $\checkmark$ & \\
\hline Peterson et al., 2010 [31] & $\checkmark$ & & & $\checkmark$ & & $\checkmark$ & & & $\checkmark$ & & $\checkmark$ & $\checkmark$ & $\checkmark$ \\
\hline Donyai et al., 2009 [32] & $\checkmark$ & & $\checkmark$ & & & & & & & & & & \\
\hline de Oliveira Martins et al., 2008 [33] & $\checkmark$ & $\checkmark$ & $\checkmark$ & $\checkmark$ & & $\checkmark$ & & & & & & & $\checkmark$ \\
\hline Taveira et al., 2006 [24] & $\checkmark$ & & & & & & & & & & & & \\
\hline Liu et al., 2008 [34] & $\checkmark$ & $\checkmark$ & $\checkmark$ & $\checkmark$ & $\checkmark$ & $\checkmark$ & & $\checkmark$ & $\checkmark$ & & & $\checkmark$ & \\
\hline Olenak et al., 2008 [35] & $\checkmark$ & $\checkmark$ & $\checkmark$ & $\checkmark$ & $\checkmark$ & $\checkmark$ & $\checkmark$ & $\checkmark$ & $\checkmark$ & & & & \\
\hline Horgan et al., 2010 [36] & $\checkmark$ & & $\checkmark$ & $\checkmark$ & $\checkmark$ & $\checkmark$ & & & & & & & $\checkmark$ \\
\hline
\end{tabular}

* Key: CVD = cardiovascular disease; SBP = Systolic Blood pressure; DBP = Diastolic Blood pressure; TC = Total Cholesterol; TG = Triglycerides; LDL = Low density lipoprotein (cholesterol); HDL = High density lipoprotein (cholesterol); TC: total cholesterol; TC: HDL = ratio of TC to HDL; BG = Blood Glucose; BMI = Body Mass Index.

Table 3. CVD risk results reported.

\begin{tabular}{ccccc}
\hline Study & n & Mean CVD risk & Standard Deviation & Outcome measure of screening tool \\
\hline Evans et al., 2010 [30] & 322 & 14.7 & not reported & cardiac death or non-fatal myocardial infarction (MI) \\
Peterson et al., 2010 [31] & 640 & 9.5 (median) & not reported & CVD risk \\
De Oliveira Martins et al., 2008 [33] & 1043 & 1.94 & 2.69 & fatal CVD \\
Liu et al., 2008 [34] & 265 & 10.9 & 9.1 & CHD \\
Horgan et al., 2010 [36] & 1130 & 11.6 & not reported & CHD \\
\hline
\end{tabular}

Table 4. CVD risk profile of study populations.

\begin{tabular}{ccccc}
\hline Study & n & Low Risk (<10\%) & Medium Risk (10\%-20\%) & High Risk (>20\%) \\
\hline Liu et al., 2008 [34] & 226 & $119(52.7 \%)$ & $73(32.3 \%)$ & $34(15.0 \%)$ \\
Olenak et al., 2008 [35] & 86 & $56(65.1 \%)$ & $23(26.7 \%)$ & $7(8.1 \%)$ \\
Horgan et al., 2010 [36] & 1130 & $201(17.8 \%)$ & $353(31.2 \%)$ & $576(51.0 \%)$ \\
Overall & 1442 & $376(26.1 \%)$ & $449(31.1 \%)$ & $617(42.8 \%)$ \\
\hline
\end{tabular}


Table 5. Outcomes measured in selected studies.

\begin{tabular}{ccccccccc}
\hline Study & $\mathbf{n}$ & $\begin{array}{c}\text { Mean age } \\
(\mathbf{y e a r s})\end{array}$ & SD & $\begin{array}{c}\text { Mean TC } \\
(\mathbf{m m o l} / \mathbf{L})\end{array}$ & SD & $\begin{array}{c}\text { Mean SBP } \\
(\mathbf{m m H g})\end{array}$ & SD & Recruitment \\
\hline $\begin{array}{c}\text { Evans et al., } \\
2010[30]\end{array}$ & 332 & 62.0 & $\mathrm{NR}$ & 4.6 & $\mathrm{NR}$ & 135.9 & $\mathrm{NR}$ & referred \\
\hline $\begin{array}{c}\text { de Oliveira } \\
\text { Martins et al. } \\
2008[33]\end{array}$ & 1043 & 53.7 & $\mathrm{NR}$ & 5.0 & 0.9 & 134.8 & 19.7 & opportunistic \\
\hline $\begin{array}{c}\text { Liu et al., } \\
\text { 2008 [34] }\end{array}$ & 265 & 57.7 & 12.1 & 5.3 & 1.0 & 142.8 & 19.2 & opportunistic \\
\hline $\begin{array}{c}\text { Olenak et al., } \\
2008[35]\end{array}$ & 86 & 59.0 & 14.2 & $\mathrm{NR}$ & $\mathrm{NR}$ & 134.1 & 15.8 & opportunistic \\
\hline $\begin{array}{c}\text { Horgan et al., } \\
2010[36]\end{array}$ & 1130 & $\mathrm{NR}$ & $\mathrm{NR}$ & 5.5 & $5.4-5.6 *$ & 129.9 & $128.8-130.9 *$ & opportunistic \\
\hline
\end{tabular}

$\mathrm{NR}=$ not reported; $* 95 \%$ Confidence Interval.

Two main factors have made it easier for pharmacists and other healthcare professionals to screen for CVD:

- The public availability of validated screening tools; and,

- The increasing availability of point-of-care testing (POCT) devices that can quickly and accurately measure cholesterol levels.

Many POCT devices currently in use differ in the results they are able to report. In many cases it is more expensive to assay for fractions of cholesterol such as HDL-C. Pharmacists can reduce costs by only testing for TC. This may inhibit the ability to use a valid screening tool. For instance, the Framingham, QRISK2 and ASSIGN screening tools all require both TC and HDL-C to screen for risk of CVD [12-14]. The SCORE screening tool can estimate risk of CVD using only TC [11]. By offering to assay full lipid profile the cost of the screening service will increase, which may reduce the number of people screened (because the cost of screening per person is increased) or reduce uptake (if the service is funded by patients). The ability of pharmacists to request laboratory testing of patient samples, which is currently not routinely possible, would be an important development and would overcome some of the challenges associated with POCT devices.

There were several limitations to this review. There were only eight papers identified as relevant and this will limit the generalisability of the findings. The inclusion of the Donyai et al. (2009) [32] paper is questionable as it only measured CVD risk and gender as compared to other studies measuring multiple outcomes. However, as this study met our inclusion criteria, it was eligible. There was no librarian involved in the literature search, which was conducted by one researcher. The researcher had been trained on literature searches, however, so this was not thought to adversely influence the results. Any ambiguity over a paper's suitability for inclusion in this review was resolved by discussion between all three researchers. It may have been productive to use other terms such as "risk calculation" as a search term, however the broad range of the search terms used meant it was thought to encapsulate all potentially relevant papers. References in retrieved papers were hand searched for other suitable papers. This review may not have captured all instances where a community pharmacist has screened 
for CVD using a screening tool. It is likely that community pharmacists have engaged in this type of screening before but have not published the results in an academic journal.

As mentioned previously, different screening tools were used and reporting of results was not consistent between studies. This means that it is not possible to compare results between different studies and use the results to estimate risk of the greater population. Furthermore for the study by Evans et al. [30], the study population was broken up into three cohorts. This study examined the effect of a pharmacist intervention. For the purposes of this review all cohorts were pooled, and only baseline screenings were included.

Referral criteria were a source of bias in this literature review. In some cases patients were only enrolled in studies if they were referred for screening or were suspected to be at risk of developing CVD. This means that the patients in this study will have a higher risk of CVD than normal.

For future work it would be recommended that the results reported would be more consistent and comprehensive. The results should describe the overall CVD risk of the population, with a measure of centrality and variability. The results should also describe the proportion of the population at low, intermediate and high risk of developing CVD. Furthermore, each risk factor measured should be described appropriately to provide as much information as possible about the population screened. By describing the population's characteristics in more detail it will allow accurate comparisons between studies and also make it easier to identify any bias in each study, such as the age or gender balance of the study population being looked at.

\section{Conclusions}

In the studies reviewed between 2008 and 2010, over 12,000 people have had a CVD risk assessment performed by a pharmacist. The fact that other screening programmes are not robustly reported in the literature makes it impossible to calculate how many people may have benefitted from pharmacist CVD screening. Opportunistic and referral-based screenings are what most pharmacists do, but they thereby miss many patients. Proactive case finding is necessary for this to be population health-relevant. What is needed is to capture those patients who do not see their physician or those of whom the physician does not think to screen for CVD risk. That is where pharmacy-based cardiovascular risk assessments would be most useful from a population health point of view and where pharmacists could have the greatest effect in improving public health.

\section{Conflicts of Interest}

The authors declare no conflict of interest.

\section{References}

1. World Health Organisation. The Global Burden of Disease: 2004 Update; World Health Organisation: Geneva, Switzerland, 2008.

2. World Health Organisation. The World Health Report 1999-Making A Difference; World Health Organisation: Geneva, Switzerland, 1999. 
3. World Health Organisation. Cardiovascular Diseases (CVDs). Available online: http://www.who.int/mediacentre/factsheets/fs317/en/ (accessed on 7 December 2013).

4. Leong, T.; McGorrian, C.; Graham, I.M. Cardiovascular Epidemiology: Background and Principles of Cardiovascular Disease Prevention. In Therapeutic Strategies in Cardiovascular Risk; Graham, I.M., D’Agostino, R.B., Sr, Eds.; Clinical Publishing: Oxford, UK, 2008; pp. 5-16.

5. Myerburg, R.J.; Kessler, K.M.; Castellanos, A. Sudden cardiac death: Epidemiology, transient risk, and intervention assessment. Ann. Intern. Med. 1993, 119, 1187-1197.

6. Oriol-Zerbe, C.; Abholz, H.H. Primary prevention of cardiovascular diseases by lipid-lowering treatment in German general practice: Results from GPs ignoring guidelines and risk calculators. Eur. J. Gen. Pract. 2007, 13, 27-34.

7. Graham, I.M.; Stewart, M.; Hertog, M.G. Factors impeding the implementation of cardiovascular prevention guidelines: Findings from a survey conducted by the European Society of Cardiology. Eur. J. Cardiovasc. Prev. Rehabil. 2006, 13, 839-45.

8. Persson, M.; Carlberg, B.; Tavelin, B.; Lindholm, L.H. Doctors' estimation of cardiovascular risk and willingness to give drug treatment in hypertension: Fair risk assessment but defensive treatment policy. J. Hypertens. 2004, 22, 65-71.

9. Kenny, N.; ní Ríain, A. Cardiovascular Disease in Women Quick Reference Guide. Available online: http://www.icgp.ie/go/library/catalogue/item/1A93A7E1-C87C-402987047A279C74B036/ (accessed on 7 December 2013).

10. National Cholesterol Education Program. Third report of the National Cholesterol Education Program (NCEP) Expert Panel on detection, evaluation, and treatment of High Blood Cholesterol in adults (Adult Treatment Panel III) final report. Circulation 2002, 106, 3143-3421.

11. Conroy, R.M.; Pyorala, K.; Fitzgerald, A.P.; Sans, S.; Menotti, A.; de Backer, G.; de Bacquer, D.; Ducimetière, P.; Jousilahti, P.; Keil, U.; et al. Estimation of ten-year risk of fatal cardiovascular disease in Europe: The SCORE project. Eur. Heart J. 2003, 24, 987-1003.

12. D’Agostino, R.B., Sr; Vasan, R.S.; Pencina, M.J.; Wolf, P.A.; Cobain, M.; Massaro, J.M.; Kannel, W.B. General cardiovascular risk profile for use in primary care: The Framingham Heart Study. Circulation 2008, 117, 743-753.

13. Hippisley-Cox, J.; Coupland, C.; Vinogradova, Y.; Robson, J.; Minhas, R.; Sheikh, A.; Brindle, P.; Predicting cardiovascular risk in England and Wales: Prospective derivation and validation of QRISK2. BMJ 2008, 336, 1475-1482.

14. Woodward, M.; Brindle, P. Tunstall-Pedoe H and estimation Sgor. Adding social deprivation and family history to cardiovascular risk assessment: The ASSIGN score from the Scottish Heart Health Extended Cohort (SHHEC). Heart 2007, 93, 172-176.

15. Dawber, T.R.; Kannel, W.B.; Revotskie, N.; Kagan, A. The epidemiology of coronary heart disease - the framingham enquiry. Proc. R. Soc. Med. 1962, 55, 265-271.

16. Graham, I.A.D.; Borch-Johnsen, K.; Boysen, G.; Burell, G.; Cifkova, R.; Dallongeville, J.; de Backer, G.; Ebrahim, S.; Gjelsvik, B.; Herrmann-Lingen, C.; et al. European guidelines on cardiovascular disease prevention in clinical practice: Executive summary: Fourth joint task force of the european society of cardiology and other societies on cardiovascular disease prevention in clinical practice (constituted by representatives of nine societies and by invited experts). Eur. Heart J. 2007, 28, 2375-2414. 
17. O’Loughlin, J.; Masson, P.; Dery, V.; Fagnan, D. The role of community pharmacists in health education and disease prevention: A survey of their interests and needs in relation to cardiovascular disease. Prev. Med. 1999, 28, 324-331.

18. Van Mil, J.W.; Schulz, M.; Tromp, T.F. Pharmaceutical care, European developments in concepts, implementation, teaching, and research: A review. Pharm. World Sci. 2004, 26, 303-311.

19. World Health Organisation. New tool to enhance role of pharmacists in health care. Available online: http://www.who.int/mediacentre/news/new/2006/nw05/en/ (accessed on 13 December 2013).

20. Dorevitch, A.; Perl, E. The impact of clinical pharmacy intervention in a psychiatric hospital. J. Clin. Pharm. Ther. 1996, 21, 45-48.

21. Cote, I.; Moisan, J.; Chabot, I.; Gregoire, J.P. Health-related quality of life in hypertension: Impact of a pharmacy intervention programme. J. Clin. Pharm. Ther. 2005, 30, 355-362.

22. Murray, M.D.; Ritchey, M.E.; Wu, J.; Tu, W. Effect of a pharmacist on adverse drug events and medication errors in outpatients with cardiovascular disease. Arch. Intern. Med. 2009, 169, 757-763.

23. Tsuyuki, R.T.; Johnson, J.A.; Teo, K.K.; Ackman, M.L.; Biggs, R.S.; Cave, A.; Chang, W.C.; Dzavik, V.; Farris, K.B.; Galvin, D.; et al. Study of Cardiovascular Risk Intervention by Pharmacists (SCRIP): A randomized trial design of the effect of a community pharmacist intervention program on serum cholesterol risk. Ann. Pharmacother. 1999, 33, 910-919.

24. Taveira, T.H.; Wu, W.C.; Martin, O.J.; Schleinitz, M.D.; Friedmann, P.; Sharma, S.C. Pharmacist-led cardiac risk reduction model. Prev. Cardiol. 2006, 9, 202-208.

25. O’Donovan, D.Ó.; Byrne, S.; Sahm, L. The role of pharmacists in control and management of type 2 Diabetes Melitus: A review of the literature. Available online: http://www.journalofdiabetology.org/Pages/Releases/FullTexts/FourthIssue/RA-1-JOD-10-023.aspx (accessed on 18 December 2013).

26. Rothman, R.L.; Malone, R.; Bryant, B.; Shintani, A.K.; Crigler, B.; Dewalt, D.A.; Dittus, R.S.; Weinberger, M.; Pignone, M.P. A randomized trial of a primary care-based disease management program to improve cardiovascular risk factors and glycated hemoglobin levels in patients with diabetes. Am. J. Med. 2005, 118, 276-284.

27. Carter, B.L.; Bergus, G.R.; Dawson, J.D.; Farris, K.B.; Doucette, W.R.; Chrischilles, E.A.; Hartz, A.J. A cluster randomized trial to evaluate physician/pharmacist collaboration to improve blood pressure control. J. Clin. Hypertens. (Greenwich) 2008, 10, 260-271.

28. McLean, D.L.; McAlister, F.A.; Johnson, J.A.; King, K.M.; Makowsky, M.J.; Jones, C.A.; Tsuyuki, R.T. A randomized trial of the effect of community pharmacist and nurse care on improving blood pressure management in patients with diabetes mellitus: Study of cardiovascular risk intervention by pharmacists-hypertension (SCRIP-HTN). Arch. Intern. Med. 2008, 168, 2355-2361.

29. Gattis, W.A.; Hasselblad, V.; Whellan, D.J.; O’Connor, C.M. Reduction in heart failure events by the addition of a clinical pharmacist to the heart failure management team: Results of the Pharmacist in Heart Failure Assessment Recommendation and Monitoring (PHARM) Study. Arch. Intern. Med. 1999, 159, 1939-1945.

30. Evans, C.D.; Eurich, D.T.; Taylor, J.G.; Blackburn, D.F. The Collaborative Cardiovascular Risk Reduction in Primary Care (CCARP) study. Pharmacotherapy 2010, 30, 766-775. 
31. Peterson, G.M.; Fitzmaurice, K.D.; Kruup, H.; Jackson, S.L.; Rasiah, R.L. Cardiovascular risk screening program in Australian community pharmacies. Pharm. World Sci. 2010, 32, 373-380.

32. Donyai, P.; van den Berg, M. Coronary heart disease risk screening: The community pharmacy Healthy Heart Assessment Service. Pharm. World Sci. 2009, 31, 643-647.

33. De Oliveira, M.S.; e Silva, S.P.; Papoila, A.L.; Caramona, M.; van Mil, F.J.; Cabrita, J. Assessment of global cardiovascular risk and risk factors in Portugal according to the SCORE ${ }^{\circledR}$ model. J. Public Health 2008, 16, 361-367.

34. Liu, Y.; Mentele, L.J.; McDonough, R.P.; Carruthers, K.M.; Doucette, W.R. Community pharmacist assessment of 10-year risk of coronary heart disease for union workers and their dependents. J. Am. Pharm. Assoc. 2008, 48, 515-517.

35. Olenak, J.L.; Calpin, M. Establishing a cardiovascular health and wellness program in a community pharmacy: screening for metabolic syndrome. J. Am. Pharm. Assoc. 2010, 50, 32-36.

36. Horgan, J.M.; Blenkinsopp, A.; McManus, R.J. Evaluation of a cardiovascular disease opportunistic risk assessment pilot ('Heart MOT' service) in community pharmacies. J. Public Health 2010, 32, 110-116.

37. Dawber, T.R.; Meadors, G.F.; Moore, F.E., Jr. Epidemiological approaches to heart disease: The Framingham Study. Am. J. Public Health Nations Health 1951, 41, 279-281.

38. Hippisley-Cox, J.; Coupland, C.; Vinogradova, Y.; Robson, J.; May, M.; Brindle, P. Derivation and validation of QRISK, a new cardiovascular disease risk score for the United Kingdom: Prospective open cohort study. BMJ 2007, 335, 136.

39. Family Heart Study Group. British family heart study: Its design and method, and prevalence of cardiovascular risk factors. Br. J. Gen. Pract. 1994, 44, 62-67.

40. Family Heart Study Group. Randomised controlled trial evaluating cardiovascular screening and intervention in general practice: Principal results of British family heart study. BMJ 1994, 308, 313-320.

41. BreastCheck Programme Report 2010-2011. Available online: http://www.breastcheck.ie/sites/ default/files/breastcheck_pogramme_report_2010-2011.pdf (accessed on 12 November 2013).

(C) 2014 by the authors; licensee MDPI, Basel, Switzerland. This article is an open access article distributed under the terms and conditions of the Creative Commons Attribution license (http://creativecommons.org/licenses/by/3.0/). 